\title{
An Innovative Low Cost EM Pollution Measurement System
}

\author{
R. Sittalatchoumy, R. Seetharaman \\ Department of Electronics and Communication Engineering, Anna University, Chennai, India \\ Email: sittalatchoumy@annauniv.edu, rseetharamanece@annauniv.edu
}

Received 30 March 2016; accepted 20 April 2016; published 29 June 2016

Copyright (C) 2016 by authors and Scientific Research Publishing Inc.

This work is licensed under the Creative Commons Attribution International License (CC BY). http://creativecommons.org/licenses/by/4.0/

(c) (i) Open Access

\begin{abstract}
Mobile phones and other electronic devices are emitting radiations that will provide harmful effects to the human health. In order to measure the radiation, an innovative low cost measurement system is proposed in this paper. The ideology is to simplify the circuit's value by converting a voltage detecting circuit to a field detecting circuit by finding an optimum resistance on trial and error basis. The requirement for a trial and error technique is to not allow too high or too low resistance which can be either short or open, resulting provides more damage to the circuit.
\end{abstract}

\section{Keywords}

Electromagnetic Radiation, Pollution, Wireless Sensor Network, Resistance, Field Measurement

\section{Introduction}

The usage of mobile phones and other electronic devices has increased tremendously. This technology improvement will provide many advantages in our day to day life. But, it has disadvantage too. The radiations from these devices will cause many problems to human health [1]. No particular system is in usage for monitoring of electromagnetic pollution in the environment. For instance, the service providers are not conscious of the radiations from the base stations/cellphone towers. Even the cellphone manufacturers are not particular about these facts [2]. These radiations provide harmful effects to the human health. Some measurements involve the usage of probe field meters manually to monitor the radiations [3] [4]. The measurement using probe field to monitor radiation is costlier and it needs additional manpower [5]. The Advantages of the Proposed System are much better compared to those of the conventional one. The setup cost of this system is low and it involves less manpower. The electric field circuit is constructed by converting a voltage detecting circuit to a field detecting circuit by finding an optimum resistance on trial and error basis. 


\section{Block Diagram}

Figure 1 shows the block diagram provides the simple idea of a $\mathrm{E}$ field measuring device wherein there is a sensing tip that detects $\mathrm{E}$ field and passes it to a A/D converter to give a digitalized output.

\section{Sensing Tip}

- Sensitivity also depends on the type of material used for the sensing edge

- Requires material with high conductivity for super and accurate detection

- Hence copper is chosen in our study

\section{Hardware Implementation}

\subsection{Circuit I}

The circuit in Figure 2 shows the components, which are soldered to the final required outlook. The circuit displays zero as an initial reading when placed near a switch board in off condition.

The circuit in Figure 3 and Figure 4 shows the measurement in real time. The display shows eighty eight when placed near a charging laptop. Thus the hardware was implemented and its working was tested and the analysis also performed.

\subsection{Circuit II}

The circuit in Figure 5 shows the detector circuit for low radiation measurement. The following points were noted.

- When the cell phone is in ideal condition, the voltage across the output terminal is zero (LED OFF). When the cell phone gets ringed or gets message, the voltage across output terminal rises. (LED ON).

- Thus the hardware was implemented and its working was tested and analysis was also performed.

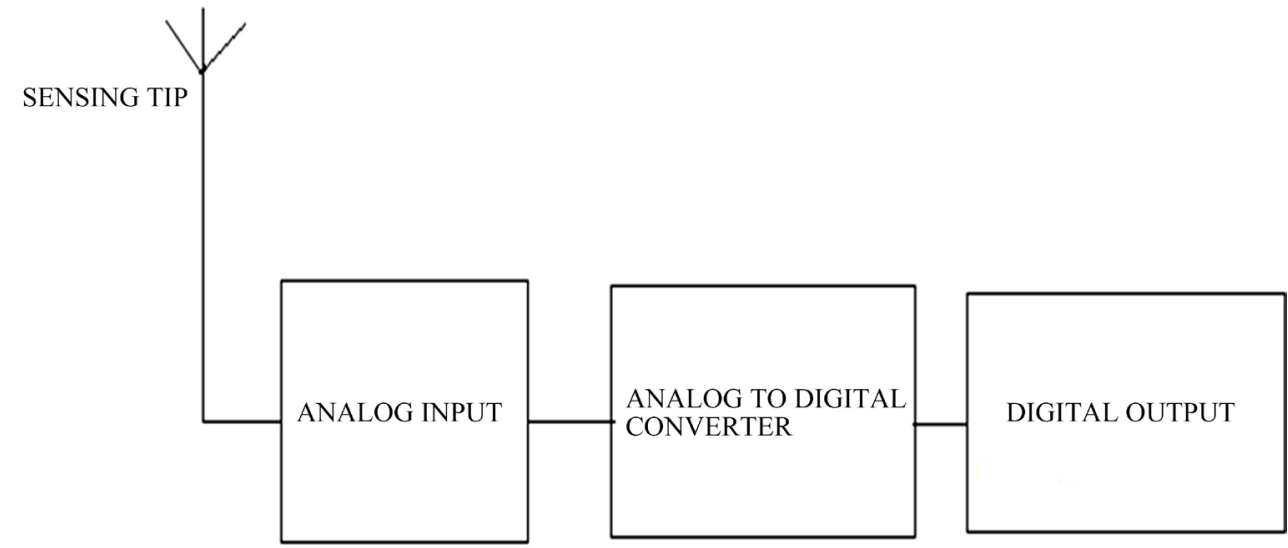

Figure 1. Block diagram of field measurements.

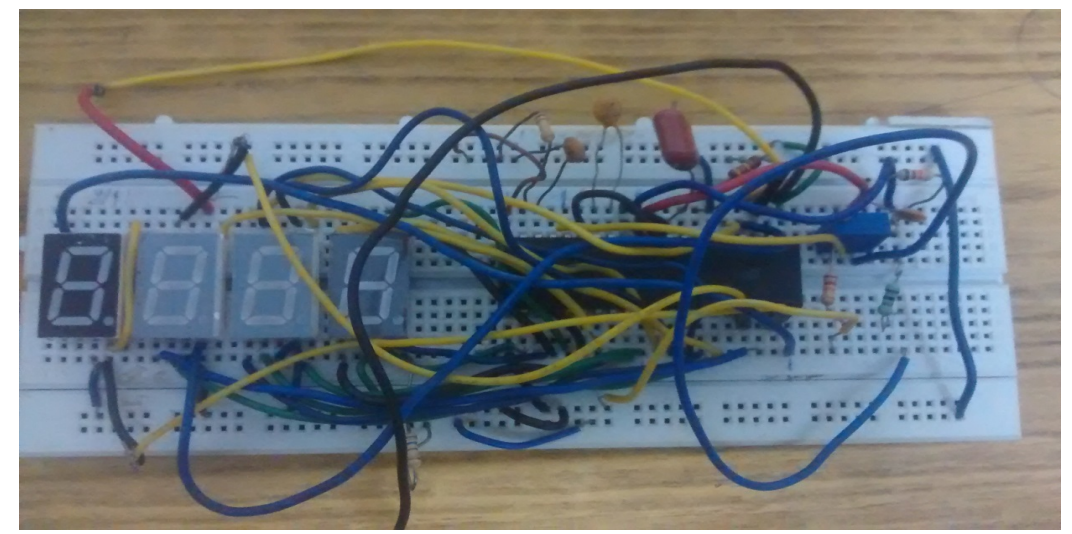

Figure 2. Breadboard implementation of electric field meter. 




Figure 3. Measured value in real time.

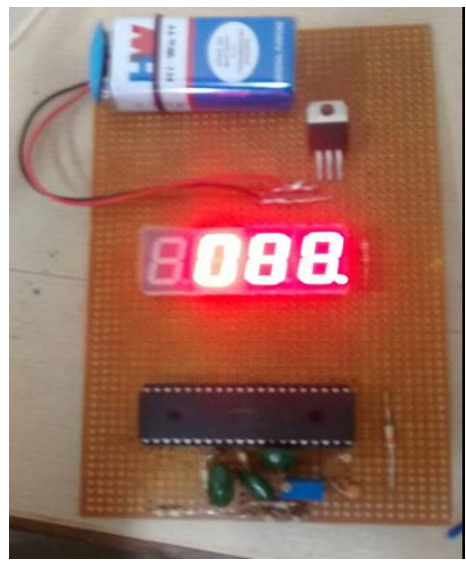

Figure 4. PCB-implementation.

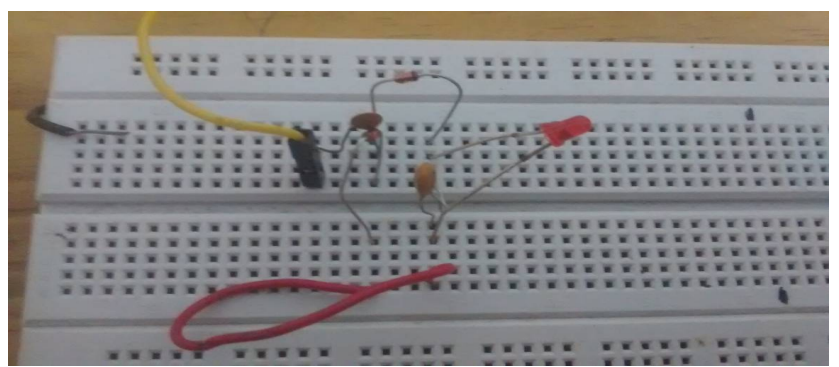

Figure 5. Detector circuit for low radiation measurement.

\section{Procedure}

The mobile phones radiate more when call-negotiation is happening with the cell tower. Once call is in progress, RF levels fall substantially. Some popular cheap brands (like Micromax) are actually radiating substantially more than good brands like Nokia and Samsung. Laptops can also radiate RF, which is more than mobile phones. iPhones radiate a lot too. They do it in approx 5 to 10 second bursts when not in use. When call is being received or in progress, they behave like any other phone, except with much more radiation.

\section{Architecture of the Network}

The system is composed by a set of $\mathrm{N}$ sensor nodes, each one equipped with a sensor circuit in any of the above mentioned circuits, a gateway node integrated with a receiver capable of collecting data from various nodes. The 
collected data is stored in a database on the receiver that can be accessed for data visualization through the display unit. The field values are measured by an isotropic antenna. The voltage signal related to the field sample is acquired by means of a I/O interface (amplification and signal conditioning) and converted into a digital quantity with a analog-to-digital converter (ADC) of the central unit at the arduino. Such a unit is provided with a microcontroller (ATMEGA328), a memory, and a radio module (RF) transmit data to the gateway. As regards to the measurement procedure, each node acts in three different states: (a) stand-by, (b) field measurement, and (c) data transmission. In the state (a), the idle configuration or sleep mode is activated and the power consumption is minimized. After a wake-up signal, the data collection is performed by means of a broadband field probe [state (b)]. In such a state, the radio of the sensor node is turned off in order to limit/avoid the interferences on the field measurements.

\section{Measurement Procedure}

Figure 6 shows the measurement procedure using Flowchart. After the field measurement and digital conversion, the field probe is switched off [state (c)] and data are transmitted to the gateway node through the radio interface. The gateway unit is connected to a server station and the information concerned with the electromagnetic emissions is then published on a web page to allow a real-time consultation. As regards to the WSN architecture, the nodes can be organized either according to a star topology or a mesh network. In the first case, the gateway node act as a master node and it receives the messages from the sensor nodes. Such an architecture is simple, robust, and does not need complex routing protocols. Moreover, star networks seem to be quite effective for BS monitoring applications, since the nodes can be deployed around the electromagnetic source.

On the contrary, mesh topologies are suitable to monitor larger areas, where the locations of the electromagnetic sources are unknown. However, a synchronization between nodes is necessary to avoid data transmissions during the measurement phases, also more energy for data transmission is usually needed because of multiple packet retransmission and overhead (multihop routing).

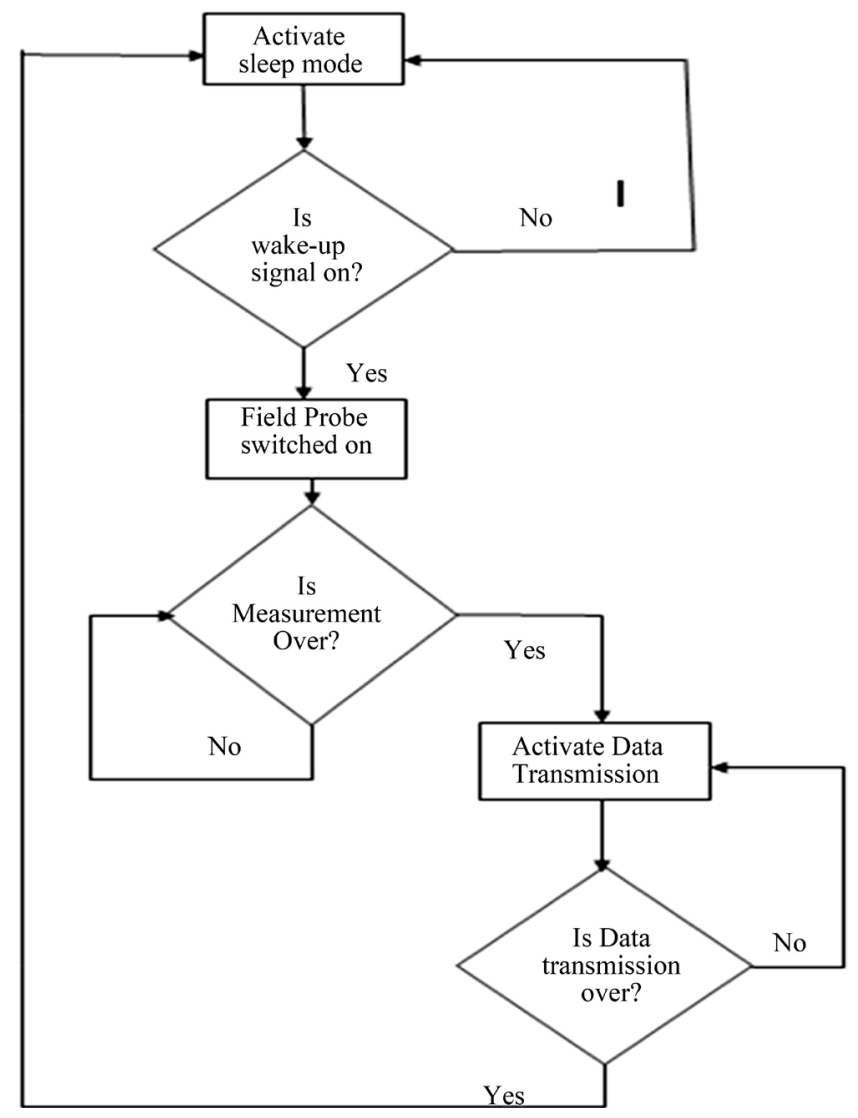

Figure 6. Flowchart of sensor nodes. 


\section{Proteus Related to the Project}

In this project a virtual sensor node is constructed by means of arduino ATMEGA328 which can be added in the proteus software using the arduino proteus library, where we can run the arduino programs. Each ATMEGA represents a sensor node which sends the data at prime number delay to the gateway receiver placed in common, which is also a arudino node. The values received at the gateway node are displayed through the virtual monitor shown in Figure 7.

\section{Results \& Analysis}

\subsection{Results-I (For Large Radiation Devices)}

The analysis was performed on a switch board by varying the sensing material to Copper and Aluminium with varied length and area. Here, the switch board is considered as a radiation source. The radiation field meter circuit is used to measure the radiation generated by the source. The distance between the radiation source and the field meter are varied and the readings are tabulated in Table 1.

\subsubsection{Configuration-1}

Source: 15A switch board

Sensing edge: Copper wire of length $30 \mathrm{~cm}$

No. of Turns: 2

Diameter of the circle: $4.4 \mathrm{~cm}$

Mode of the switch: ON

From the tabulation, it is clear that, when the source is nearer to the field meter, the radiation is more and the distance is more, the radiation is less. The readings are plotted in Figure 8. As the distance increases, the radiation

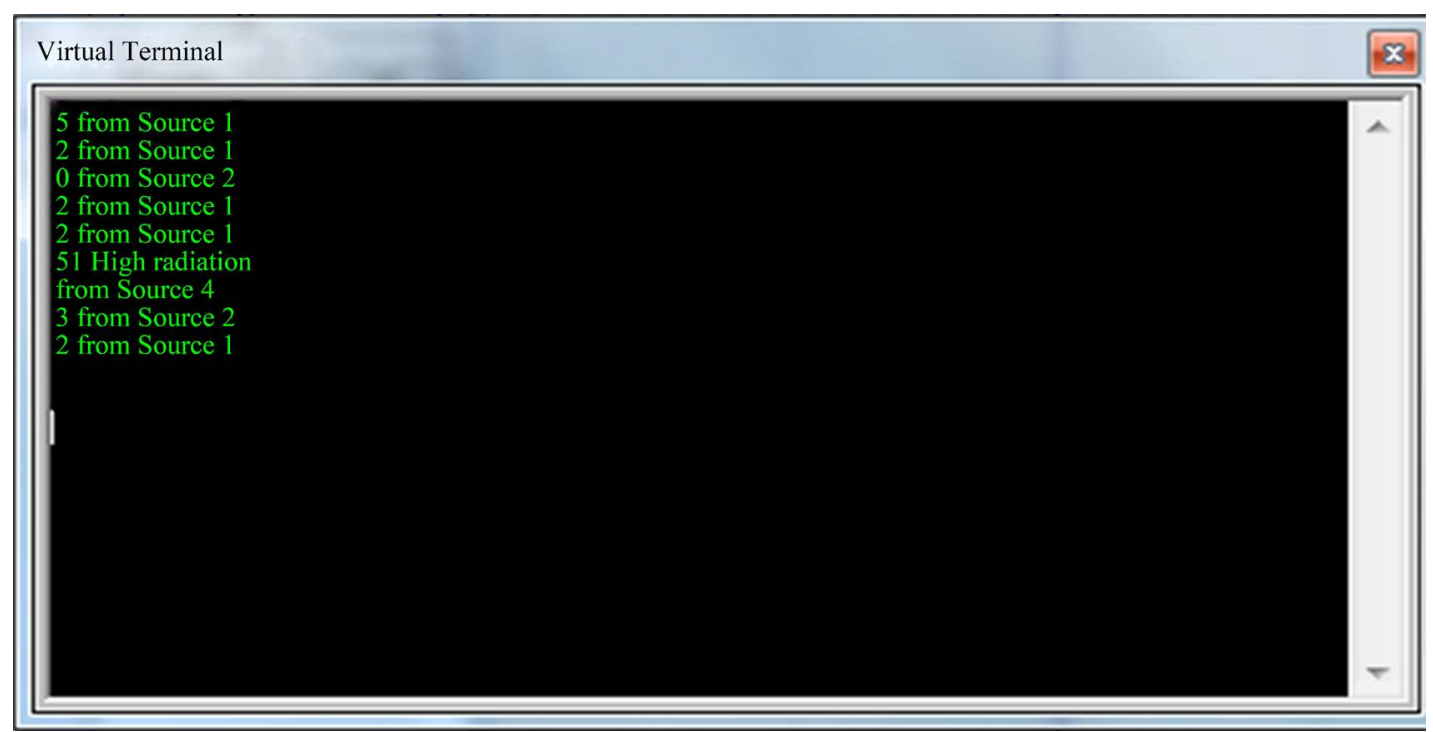

Figure 7. Serial monitor of Proteus.

Table 1. Copper wire $(30 \mathrm{~cm})$ on mode.

\begin{tabular}{ccc}
\hline S.No & Distance from the source $(\mathrm{cm})$ & Electric field $(\mathrm{v} / \mathrm{cm})$ \\
\hline 1 & 0 & 145 \\
2 & 5 & 66 \\
3 & 8 & 37 \\
4 & 10 & 27 \\
5 & 12 & 13 \\
6 & 15 & 10 \\
7 & 18 & 7 \\
\hline
\end{tabular}


are decreases and at one point it is approaches the minimum value. From the results, it is appreciating that, at least a minimum distance will maintain form the radiating source to avoid unwanted radiation.

\subsubsection{Configuration-2}

Source: 15A switch board

Sensing edge: Copper wire of length $30 \mathrm{~cm}$

No. of Turns: 2

Diameter of the circle: $4.4 \mathrm{~cm}$

Mode of the switch: OFF

The above configuration is set up and the readings are noted in Table 2 and response is plotted in Figure 9.

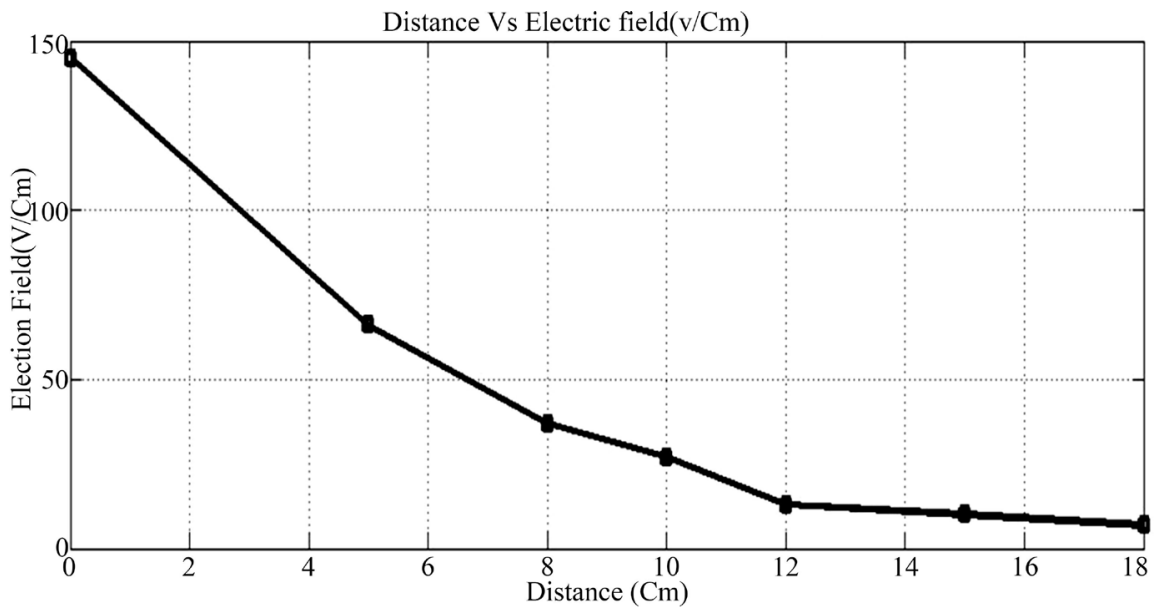

Figure 8. Copper wire $(30 \mathrm{~cm})$ on mode.

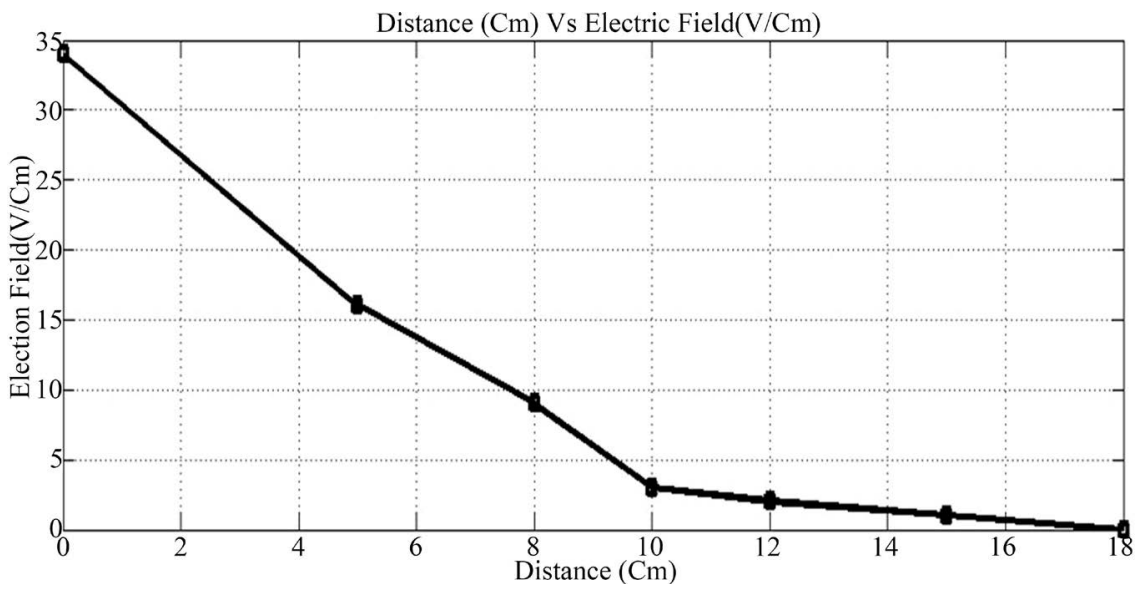

Figure 9. Copper wire $(30 \mathrm{~cm})$ off mode.

Table 2. Copper wire $(30 \mathrm{~cm})$ off mode.

\begin{tabular}{ccc}
\hline Sl.No. & Distance from the source $(\mathrm{cm})$ & Electric field $(\mathrm{V} / \mathrm{cm})$ \\
\hline 1 & 0 & 34 \\
2 & 5 & 16 \\
3 & 8 & 9 \\
4 & 10 & 3 \\
5 & 12 & 2 \\
6 & 15 & 1 \\
7 & 18 & 0 \\
\hline
\end{tabular}


From the readings, it is realize that, when the radiating source is in Off condition also, it will emits radiation. But, the radiation level is low, compared to its On condition.

\subsubsection{Configuration-3}

Source: $15 \mathrm{~A}$ switch board

Sensing edge: Copper wire of length $100 \mathrm{~cm}$

No. of Turns: 7

Diameter of the circle: $4.4 \mathrm{~cm}$

Mode of the switch: ON

The copper wire length and the turns are varied and the above process are repeated and the readings are noted in Table 3. From the graph in Figure 10 shows that, the sensitivity increases as the length increases.

The graph in Figure 11 shows that, the radiation is low in OFF condition compared to ON condition.

Table 3. Copper wire $(100 \mathrm{~cm})$ on mode.

\begin{tabular}{ccc}
\hline Sl.No. & Distance from the source $(\mathrm{cm})$ & Electric field $(\mathrm{V} / \mathrm{cm})$ \\
\hline 1 & 0 & 435 \\
2 & 5 & 115 \\
3 & 8 & 56 \\
4 & 10 & 35 \\
5 & 12 & 25 \\
6 & 15 & 12 \\
7 & 18 & 8 \\
\hline
\end{tabular}

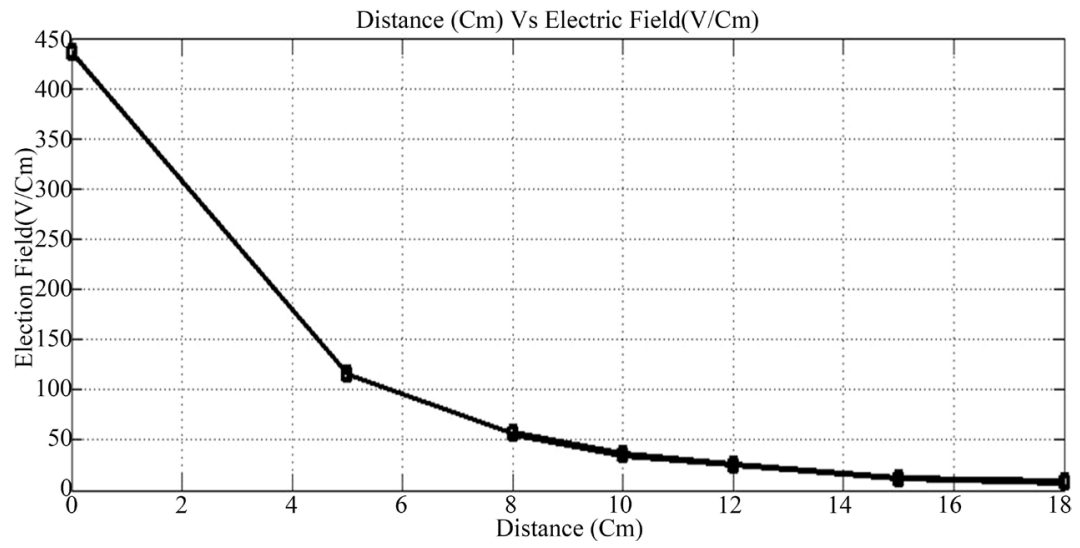

Figure 10. Copper wire $(100 \mathrm{~cm})$ off mode.



Figure 11. Copper wire $(100 \mathrm{~cm})$ on mode. 


\subsubsection{Configuration-4}

Source: $15 \mathrm{~A}$ switch board

Sensing edge: Copper wire of length $100 \mathrm{~cm}$

No. of Turns: 7

Diameter of the circle: $4.4 \mathrm{~cm}$

Mode of the switch: OFF

Now, the switch is closed (OFF mode) for the same configuration and the above process are repeated and the readings are noted in Table 4. From the graph in Figure 10 shows that, the radiation is low in OFF condition compared to ON condition.

\subsubsection{Configuration-5 Source: 15A Switch Board}

Sensing edge: Flat Aluminium electrode of area $9 \times 5 \mathrm{~cm}$

Mode of the switch: ON

\subsubsection{Configuration-6}

Source: $15 \mathrm{~A}$ switch board

Sensing edge: Flat Aluminium electrode of area $9 \times 5 \mathrm{~cm}$

Mode of the switch: OFF

The same procedure is repeated for the Aluminium Wire and the readings are tabulated in Table 5 and Table 6 respectively. The graphs in Figure 12 and Figure 13 reveal that copper wire has less radiation than the Aluminium wire. Since the conductivity of the copper wire is more and the cost of the copper wire is less. So, it can be preferred Copper than Aluminium for low cost system.

\section{Table 4. Copper wire $(100 \mathrm{~cm})$ off mode.}

\begin{tabular}{ccc}
\hline Sl.No. & Distance from the source $(\mathrm{cm})$ & Electric field $(\mathrm{V} / \mathrm{cm})$ \\
\hline 1 & 0 & 80 \\
2 & 5 & 21 \\
3 & 8 & 10 \\
4 & 10 & 6 \\
5 & 12 & 4 \\
6 & 15 & 2 \\
7 & 18 & 1 \\
\hline
\end{tabular}

Table 5. Aluminium wire $(100 \mathrm{~cm})$ on mode.

\begin{tabular}{ccc}
\hline Sl.No. & Distance from the source $(\mathrm{cm})$ & Electric field $(\mathrm{V} / \mathrm{cm})$ \\
\hline 1 & 0 & 707 \\
2 & 5 & 233 \\
3 & 8 & 103 \\
4 & 10 & 66 \\
5 & 12 & 44 \\
6 & 15 & 27 \\
7 & 18 & 13 \\
\hline
\end{tabular}

Table 6. Aluminium $(100 \mathrm{~cm})$ off mode.

\begin{tabular}{ccc}
\hline Sl.No. & Distance from the source $(\mathrm{cm})$ & Electric field $(\mathrm{V} / \mathrm{cm})$ \\
\hline 1 & 0 & 257 \\
2 & 5 & 35 \\
3 & 8 & 15 \\
4 & 10 & 10 \\
5 & 12 & 6 \\
6 & 15 & 4 \\
7 & 18 & 2 \\
\hline
\end{tabular}




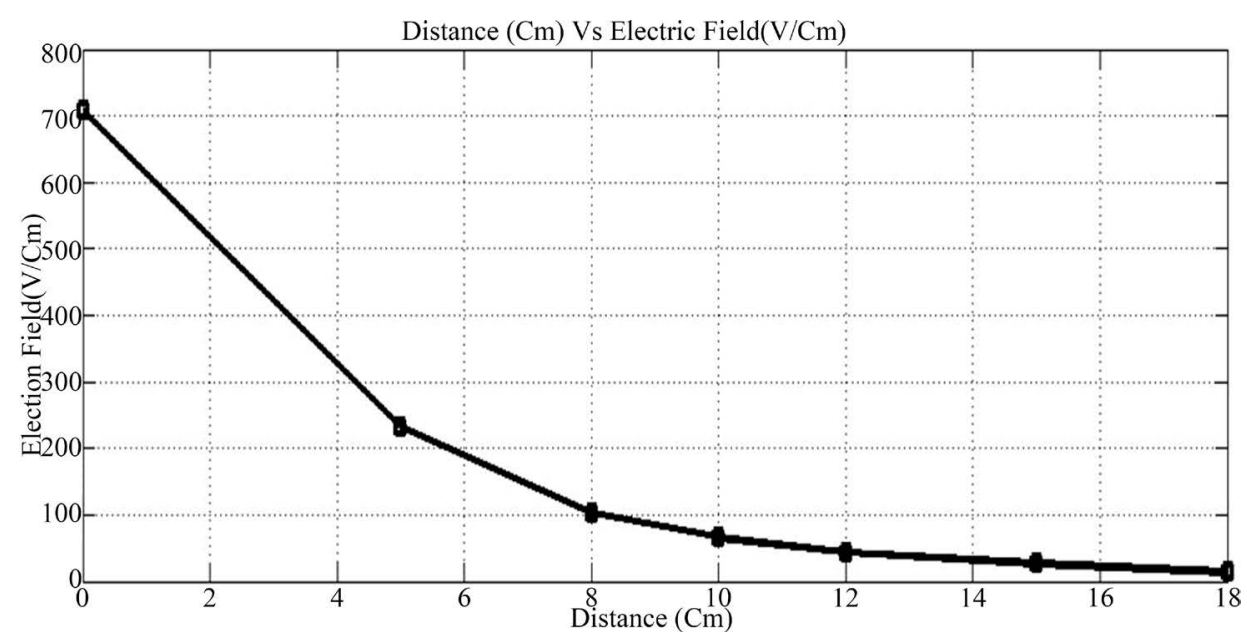

Figure 12. Aluminium $(100 \mathrm{~cm})$ on mode.

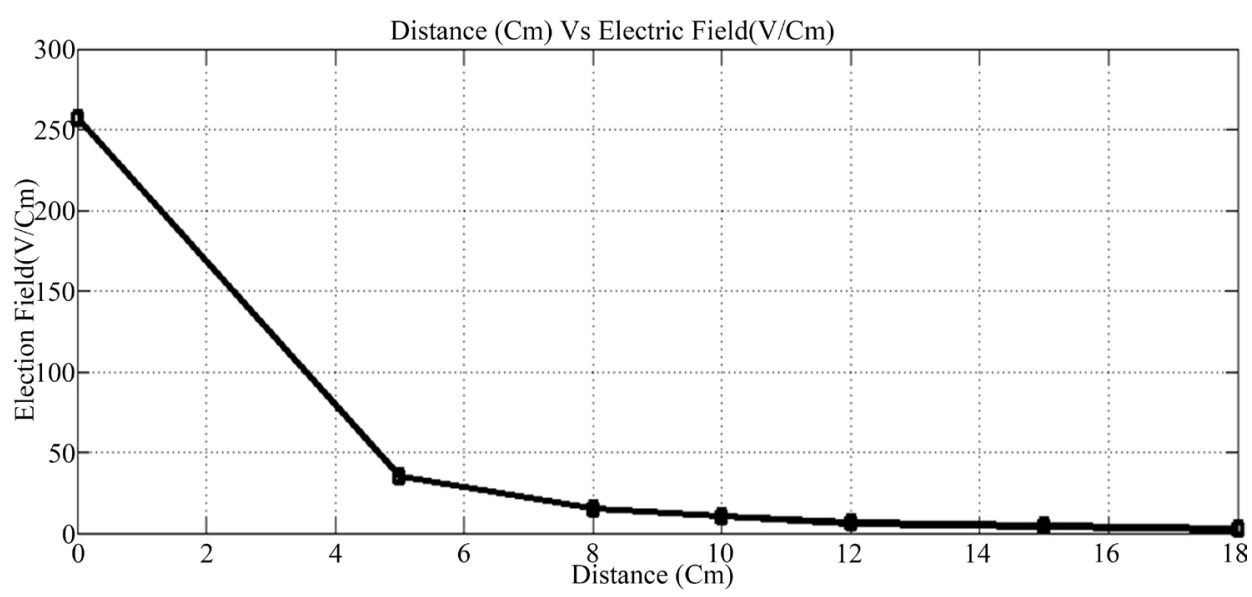

Figure 13. Aluminium $(100 \mathrm{~cm})$ off mode.

\subsection{Results-II (For Small Radiation Devices)}

For high frequency mobile phone radiation where the magnitude variation is very small, the tabulation from the sensor circuit is as follows.

\section{Radiation for Different Mobile Phones}

The radiation measurement of different Mobile phone was carried out and the readings are noted in Table 7. The radiation between the two mobile phones was performed. The Mobile phone was kept in parallel to the radiation source and Perpendicular with the radiating source and the effects are noted in Table 8 and Table 9.

The readings are plotted in Figure 14 and Figure 15 respectively. From the graph, it is clear that, whenever the number of Mobile phones increases, proportionally the radiation effect also increases.

\section{Conclusions and Future Work}

In this paper a simple and low cost radiation measurement system has been presented. The proposed system consists of a set of wireless sensor nodes, each node equipped with the field detector circuit with sensing tip. The detected electromagnetic radiation, which is analog in nature, is converted into corresponding voltage levels by using analog to digital converter (ADC). The simulation is carried out with two different sensing tips of variable length and switch board as a radiating source. The experimental results show that the radiation level is high nearby the source and decreases gradually as the distance increases from the source. When the length of the copper wire is increased, the emitted radiation level also increases. Moreover the Aluminium wire leads to more 
Table 7. Electric field level.

\begin{tabular}{ccccc}
\hline Models & Cellkon & Micromax & Motto & Samsung \\
\hline Electric field Single mobile phone $(\mathrm{V} / \mathrm{m})$ & $2.0-3.5$ & $2.4-2.6$ & $2.7-3.0$ & $2.3-2.8$ \\
Double mobile phones & $2.7-3.5$ & $2.8-3.1$ & $3.0-3.2$ & $2.5-2.9$ \\
\hline
\end{tabular}

Table 8. Parallel radiating sources.

\begin{tabular}{ccc}
\hline Distance from the radiating source $(\mathrm{cm})$ & Single source $(\mathrm{V} / \mathrm{cm})$ & Double Source $(\mathrm{V} / \mathrm{cm})$ \\
\hline 0 & 24.2 & 44 \\
10 & 4.5 & 8 \\
20 & 2.5 & 4 \\
25 & 2.1 & 3.8 \\
30 & 2.0 & 3.1 \\
40 & 2.0 & 2.6 \\
50 & 1.9 & 2.3 \\
60 & 1.9 & 2.1 \\
90 & 1.8 & 1.8 \\
\hline
\end{tabular}

Table 9. Perpendicular radiating sources.

\begin{tabular}{ccc}
\hline Distance from the radiating source $(\mathrm{cm})$ & Single source $(\mathrm{V} / \mathrm{cm})$ & Double Source $(\mathrm{V} / \mathrm{cm})$ \\
\hline 0 & 30 & 50 \\
10 & 6.1 & 10.8 \\
20 & 3.2 & 6.2 \\
30 & 2.7 & 5.2 \\
40 & 2.5 & 4 \\
50 & 2.1 & 2.7 \\
60 & 1.9 & 2.1 \\
90 & 1.8 & 1.8 \\
\hline
\end{tabular}

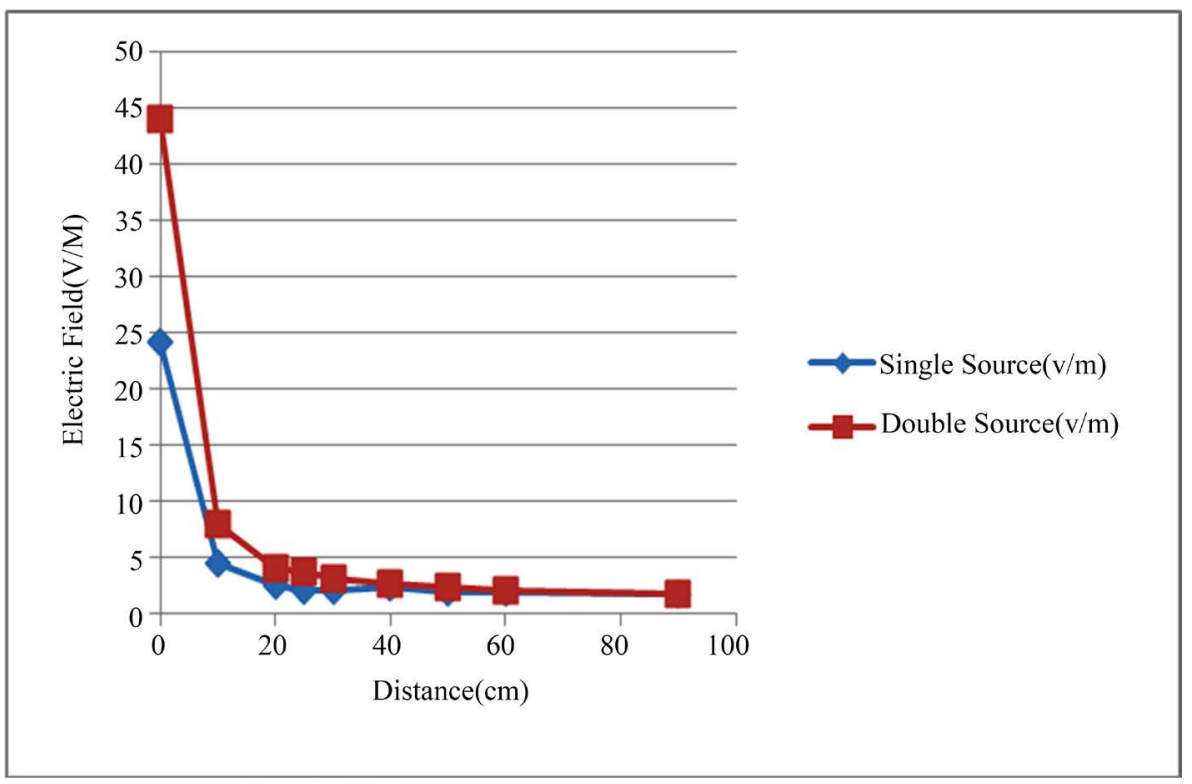

Figure 14. Parallel radiating sources. 


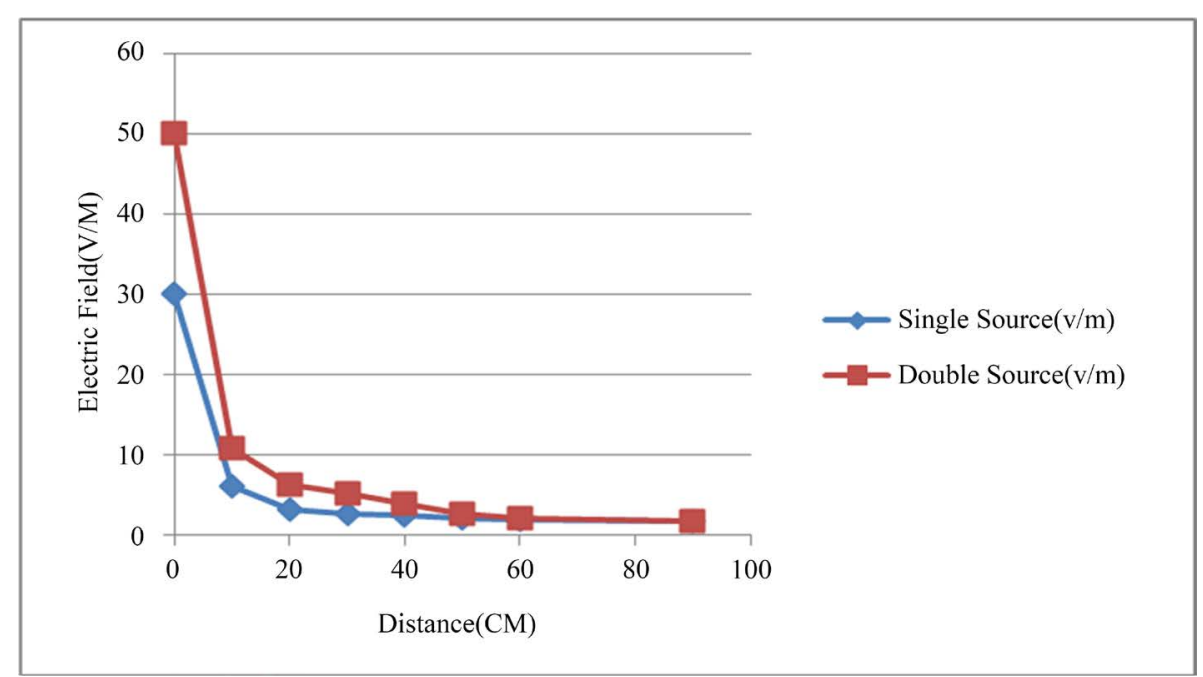

Figure 15. Perpendicular radiating sources.

radiation than copper.

The experimental results reveal that, when the number of radiating sources increases the amount of emitted radiation also increases.

\section{References}

[1] Ioriatti, L., Martinelli, M., Viani, F., Benedetti, M. and Massa, A. (2009) Real-Time Distributed Monitoring of Electro Magnetic Pollution in Urban Environments. IEEE International Geoscience and Remote Sensing Symposium, IGARSS, 5, 100-103.

[2] Wadhwa, C.L. (2007) High Voltage Engineering. 2nd Edition, New Age International Private Limited, New Delhi.

[3] Shen, X.L., Wang, F., Zeng, R. and Geng, Y.N. (2012) Lightning Impulse Electric Field Measurement in Long Air Gap Based on the Integrated Electro-optical Measurement System. Proceedings of the 2012 International Conference on High Voltage Engineering and Application, Shanghai, 17-20 September 2012, 30-34. http://dx.doi.org/10.1109/ICHVE.2012.6357003

[4] William McNulty (2011) Voltage Detection and Indication by Electric Field Measurement. HD Electric Company.

[5] http://rookieelectronics.com/sensor-rf-radiation-detector/

\section{Scientific Research Publishing}

\section{Submit or recommend next manuscript to SCIRP and we will provide best service for you:}

Accepting pre-submission inquiries through Email, Facebook, Linkedin, Twitter, etc A wide selection of journals (inclusive of 9 subjects, more than 200 journals)

Providing a 24-hour high-quality service

User-friendly online submission system

Fair and swift peer-review system

Efficient typesetting and proofreading procedure

Display of the result of downloads and visits, as well as the number of cited articles

Maximum dissemination of your research work

Submit your manuscript at: http://papersubmission.scirp.org/ 